\title{
Effect of psychoeducation based on choice theory on marital satisfaction and increasing couples' adaptability: a double-blind randomized clinical trial
}

\author{
Atefeh Soltanifar ${ }^{1}$, Fatemeh Moharari ${ }^{1}$, Zahra Rajai $^{2}$, Maliheh Ziaee ${ }^{3}$, Zanireh Salimi ${ }^{2}$
}

\begin{abstract}
${ }^{1}$ M.D., Psychiatrist, Associate Professor, Department of Psychiatry, Psychiatry and Behavioral Sciences Research Center, Ibn-e-Sina Hospital, School of Medicine, Mashhad University of Medical Sciences, Mashhad, Iran

${ }^{2}$ M.D., Psychiatry Resident, Department of Psychiatry, Psychiatry and Behavioral Sciences Research Center, Ibn-eSina Hospital, School of Medicine, Mashhad University of Medical Sciences, Mashhad, Iran

${ }^{3}$ Community Medicine Specialist, Assistant Professor of Community Medicine, Department of Community Medicine, School of Medicine, Social Determinants of Health Research Center, Gonabad University of Medical Sciences, Gonabad, Iran
\end{abstract}

\section{Type of article: Original}

\begin{abstract}
Background: Considering the high prevalence of couples' complaints due to marital conflicts, it is important to improve marital satisfaction in order to set up and increase the social and individual mental health and the functional necessity of the family as the basis foundation for promoting the community's potential capability.

Objective: This study was conducted to use reality therapy based on choice theory to assess treatment outcomes in couples with marital conflict and dissatisfaction.

Methods: In this double-blind randomized clinical trial, 20 couples (40 individuals) referring from psychiatric and psychological clinics of Mashhad city between December 2017 to September 2018 were randomly allocated into two groups of intervention and control. After completing the 115-item ENRICH Marital Satisfaction Scale, Family Assessment Device (FAD) and Dyadic Adjustment Scale (DAS) questionnaires, the intervention group received Glasser's theory of choice psychoeducation while a control group received supportive psychotherapy by a psychiatrist and a couple therapist for eight sessions in eight consecutive weeks (two hours each session). The evaluation was carried out at the beginning of the study, week 1, week 8 (immediately after completing the intervention) and week 12 (four weeks after completing the intervention). Data were analyzed by IBM-SPSS 21. A $\mathrm{p} \leq 0.05$ was considered significant in examining the hypotheses.

Results: Eighteen couples (36 individuals) continued until the end of the study. The mean ages in the intervention and control groups were $34.02 \pm 1.15$ years and $36.7 \pm 3.2$ respectively. Participants' clinical features including age, sex, education, couple therapy history, number of children, and familial relationship were not significantly different between the two groups. The results of ENRICH and family function scale showed that there was a significant difference between the two groups immediately and 4 weeks after completion of the intervention $(\mathrm{p}=0.002)$

Conclusion: The results of this study suggested that psychoeducation based on choice theory has a significant effect on marital adaptability and satisfaction as well as family function.

Trial registration: The current study was registered at the Iranian Registry of Clinical Trials (http://wwwirct.ir) (ID: IRCT20180504039519N1).

Funding: No financial support was received by authors for the research.

Keywords: Theory of choice, Marital adaptability, Marital satisfaction, Couple
\end{abstract}

\section{Corresponding author:}

Dr. Zanireh Salimi, Department of Psychiatry, Psychiatry and Behavioral Sciences Research Center, Ibn-e-Sina Hospital, School of Medicine, Mashhad University of Medical Sciences, Mashhad, Iran

Tel: +98.9153053528, Fax: +98.5137112545, Email: zaniresalimi@yahoo.com

Received: December 12, 2018, Accepted: April 26, 2019, Published: June 2019

iThenticate screening: April 26, 2019, English editing: May 16, 2019, Quality control: May 17, 2019

This article has been reviewed / commented by four experts

Research project approval: Proposal no. 951702

Ethics approval: Mashhad University of Medical Sciences (Ref: IR.mums.FM.rec.1396.151, on Jun 14, 2017)

(C) 2019 The Authors. This is an open access article under the terms of the Creative Commons Attribution-NonCommercialNoDerivs License, which permits use and distribution in any medium, provided the original work is properly cited, the use is non-commercial and no modifications or adaptations are made. 
Abbreviations / Acronyms:

DAS: Dyadic Adjustment Scale; ENRICH: Enriching and Nurturing Relationship Issues, Communication, and Happiness; FAD: Family Assessment Device

\section{Introduction}

Undoubtedly, one of the most important decisions that every person takes throughout his life is made when choosing a spouse. Considering that marital satisfaction is one of the most important aspects of marriage, marital satisfaction is one of the most important determinants of a healthy family function (1). Based on the opinions of most scholars in this field, this phenomenon requires functional and effective communication. Based on this, communication problems are the most common and destructive issues in marriage failures (2-4). Unsatisfying marriage is the most common complaint that increases the divorce rate, it should be noted that divorce is not the only sign of an unwelcome marriage; furthermore, numerous couples choose not to get divorced and remain in an unhappy marriage. This issue may have various consequences like reducing mental and physical health of the spouses, psychological distress including feeling loneliness, emptiness, depression of one or both partners, addiction, low self-esteem, difficulty in performing parental duties, disturbance of social relationships and performance of spouses, developing disruptive behavior among children, verbal and physical aggression and ,at last, the divorce itself (5-11). According to available statistics, divorce rates have increased in recent years, from 53,797 during 2000 to 163,569 during 2014 (12). Therefore, effective interventions to increase the satisfaction and intimacy of couples should be considered, detecting efficient and effective scientific methods for obtaining this purpose may enhance the satisfaction of existing marriages, thus preventing the adverse consequences of family disturbances. Couple therapy interventions are highly effective in helping couples in preventing conflicts, correcting marital dissatisfaction and abrupt intimacy, increasing family function and enriching marital relationships. One of the approaches that can be highly effective in couple therapy and marital issues is reality therapy and Glasser's theory of choice, a method for counseling, psychotherapy and psycho education (13).

Learning the choice theory and reality therapy teaches the skills that individuals can choose in order to behave responsibly, it also teaches the impact of behavior on emotions, and helps to improve behavioral disorder. The choice theory emphasizes that we can only control ourselves, and not others, and by controlling our behavior and correcting communication problems, many psychological problems are solved. The effect of choice theory on improving interpersonal relationships in other psychiatric disorders and in adults has been proven in previous studies (13-19). In Glasser's opinion, marital conflict is due to the selection of irrational and improper behaviors in marital relations, conflicts of interests, unreliability of desires and the inability for proper behavioral assessment. In his view, for solving marital conflicts, couples should be helped to asses and design reality-based behaviors that reduce conflicts and strengthen the principle of marriage. In fact, marital intimacy depends on understanding the basic principle of choice theory in choosing an autonomous and mature conflict resolution. Glasser's Reality Therapy is one of the most common therapeutic interventions for describing individuals in determining behavioral rules and how to achieve satisfaction, happiness and success (19-21). A study by Darbay et al. evaluated the effectiveness of the concepts of choice theory and therapeutic reality techniques on increasing the intimacy of maladaptive couples referring to the counseling centers in 8 sessions of training, by using marital adjustment and marital intimacy tests before and after training (22). They showed that the teachings of the concepts of the theory of choice and reality therapy techniques reduce the couples' inadaptability, and their general intimacy is increased in the post-test and follow-up. However, research conducted at academic centers shows that this issue has so far, been less studied in Iran, and is a subject to which our politicians, researchers and psychotherapists have been indifferent. Therefore, this study, with the aim of investigating the effects of this theory on marital satisfaction and couples' adaptability and assessing the possible therapeutic outcomes, has been designed. We hope that the results of this essay may ultimately provide a basis for the application of this theory in our country.

\section{Material and Methods}

\subsection{Trial design and participants}

This study was a double blind randomized clinical trial that was conducted from December 2017 to September 2018. Participating couples, data analysts and outcome evaluators were kept blind in the study. This clinical trial was conducted in a teaching hospital (Ibn-E-Sina Hospital and its integrated psychiatric and psychological clinics). IbnE-Sina Hospital is the main psychiatry hospital of Khorasan province and the referral center in the eastern part of Iran, and it is affiliated with Mashhad University of Medical Sciences. The study population was comprised of 68 patients referring from psychiatric private clinics and psychological clinics with complaints of marital problems for at least 8 months. Figure 1 shows the CONSORT flow diagram of the trial. 


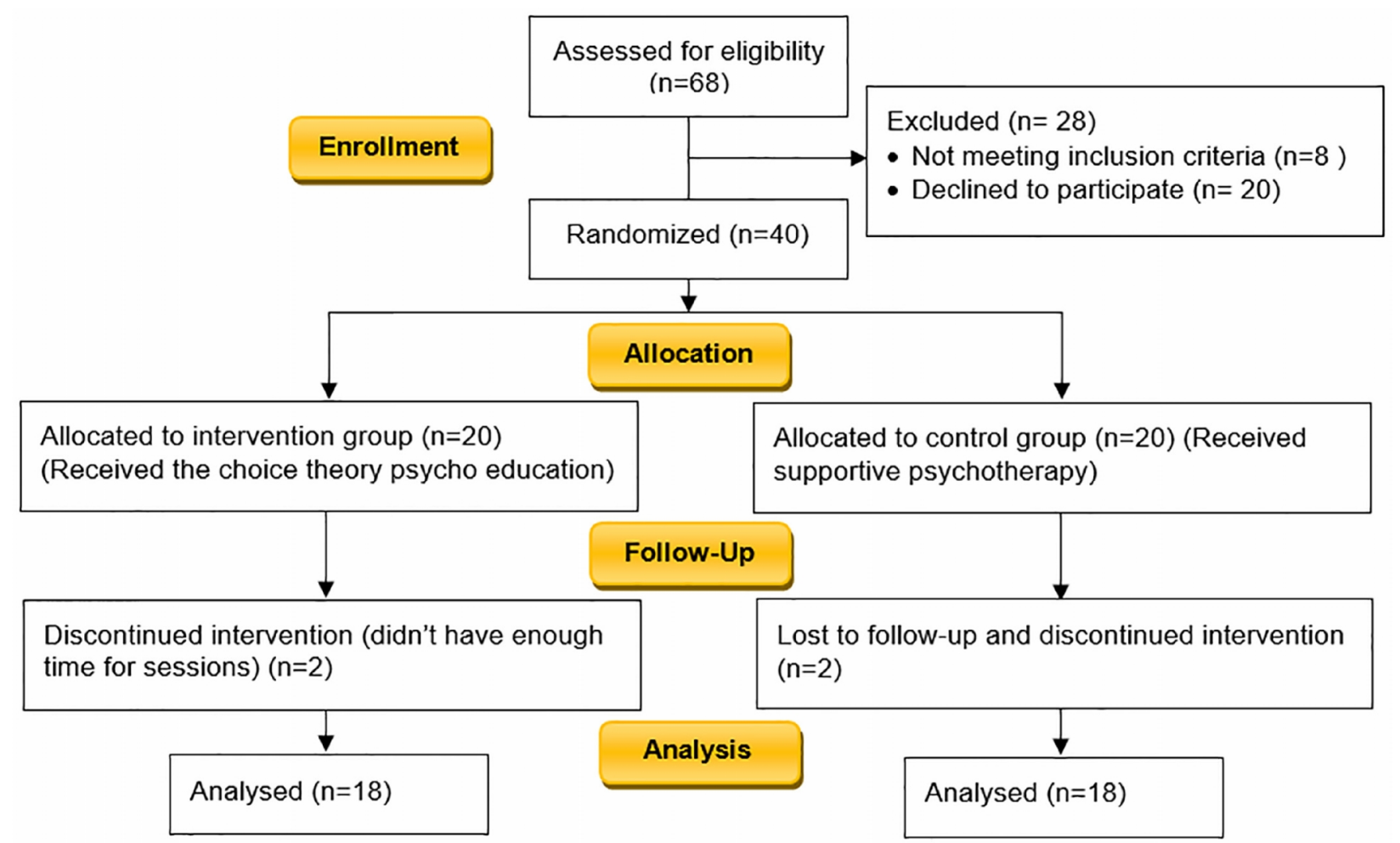

Figure 1. CONSORT flow diagram of the trial

\subsection{Sample size}

The sample size was calculated as five couples on the basis of the mean difference test in the intervention and control groups and previous study (23). Considering the $10 \%$ drop in the participants due to couples' conditions and our relatively long-term psychotherapy intervention as well as taking into account similar studies, 18 (nine couples in intervention group) were considered. The final sample size, with reference to the amount of tolerated error in the first and second type (in total and in each research group plus the probable duration for achievement) was 36 (eighteen participants per group) using the following formula:

$\mathrm{n}=\left(\mathrm{Z}_{1-\alpha / 2}+\mathrm{Z}_{1-\beta}\right)^{2}\left(\sigma_{1}^{2}+\sigma_{2}^{2}\right) /\left(\mu_{1}-\mu_{2}\right)^{2}$

Where:

$n=10 ; a=0.05, \beta=0.2, Z_{1-a / 2}=1.961150, Z_{1-B}=0.841623, \mu_{1}=52.3, \mu_{2}=39.05$ (based on Amani's study) (23).

\subsection{Selection criteria}

The following were set as the inclusion criteria for participation in this study:

1) At least one year has passed since the marriage.

2) No addiction problem has been detected.

3) Each couple was willing to attend the trial up to the end of the course.

4) The level of education was not lower than diploma.

5) Couple's marital satisfaction score was equal or less than average.

6) Couple's family function score was equal or less than average.

7) Couple's Spinner marital adaptability score was equal or less than average.

8) Both couples completed the informed consent.

The exclusion criteria for participation in this study were:

1) Unwillingness to continue the research project.

2) Suffering from interfering systemic or psychiatric disorders.

\subsection{Randomization and blinding}

From 68 patients referring from psychiatric private clinics and psychological clinics, 14 couples were excluded from the study due to their unwillingness to participate or meet the exclusion criteria. The remaining 20 couples (forty 
individuals) were randomly allocated into intervention and control groups using a random number table. To assign an equal sample number to each group, block randomization was used. From six blocks of the form AABB, ABAB, ABBA, BAAB, BABA and BBAA, five blocks were selected randomly and each couple received its treatment based on this randomization. After completing the 115-item ENRICH Marital Satisfaction Scale, The Family Assessment Device (FAD) and Dyadic Adjustment Scale (DAS) questionnaires (each questionnaire had been translated to the patients' native language (Persian) and their reliability and validity had been checked in previous studies $(6,12,22)$ both groups participated in different types of psychotherapy. Participating couples, data analysts and outcome evaluators were kept blind.

\subsection{Intervention and measurements}

In intervention group, participants have been educated Glasser's the theory of choice by psychiatrist and couple therapist for 8 sessions in eight consecutive weeks (two hours for each session). Learning the choice theory and reality therapy teaches the skills that individuals can choose to behave responsibly, as well as the impact of behavior on emotions, and helps to improve their behavioral disorder. The choice theory emphasizes that we can only control ourselves, and not others, by controlling our behavior and correcting communication problems, many psychological problems are solved. In the control group, couples received supportive psychotherapy by psychiatrists and couple therapists for eight sessions in eight consecutive weeks (two hours for each session). The evaluation was carried out at the beginning of the study, week 1 , week 8 and week 12 after completion of the sessions. The therapeutic outcomes in both intervention and control groups were evaluated by a statistical consultant.

\subsection{Outcomes and controlling the confounders}

The primary outcomes of our analyses were the level of marital satisfaction evaluating by the ENRICH Marital Satisfaction Scale and the level of family function evaluating by the General Functioning Scale or McMaster Family Assessment Device (FAD) while the secondary outcomes were the level of marital adaptability evaluating by the Dyadic adjustment scale (DAS) questionnaire. We prevented the potential confounding factor of this study (the unequal presence of couples in sessions) by justifying couples for joining sessions regularly. Since the potential confounding variables were controlled during the research design, there were no need for additional measures by multivariate statistics during the data analysis.

\subsection{Statistical analysis}

IBM(C) SPSS $\odot$ Statistics version 21 (IBM $\odot$ Corp., Armonk, NY, USA) was used for data analysis. Data were analyzed using descriptive statistics, t-test, Mann-Whitney $U$, and Chi-square test. The value of $p<0.05$ was considered as statistically significant.

\subsection{Research ethics}

After obtaining the scientific approval by the psychiatric department, the ethics of current study was approved by Ethics Committee of Mashhad University of Medical Sciences (Ref: IR.mums.FM.rec.1396.151) on Jun 14, 2017. All the procedures in this study were in conformity with the Declaration of Helsinki and were approved by the local Human Research Ethics Committee, as mentioned before. The study was registered at the Iranian Registry of Clinical Trials (ID: IRCT20180504039519N1, website: http://www.irct.ir). The participants were completely informed about the aim and the method of our study, and oral and written informed consents were obtained from them prior to the study and each participant was free to withdraw from the study at any time without any obligation or question. All participants' information was kept confidential and participants who received supportive therapy were added to the choice theory psychoeducation waiting list after completion of the study.

\section{Results}

Mean age in the intervention and control groups were $34.02 \pm 1.15$ years and $36.7 \pm 3.2$ years respectively. In terms of education, $83.3 \%$ of the intervention group and $50 \%$ of the control group had a Bachelor's degree or higher. Evaluating the age $(\mathrm{p}=0.15)$ no significant difference was reported. A significant difference was detected comparing the number of years married $(\mathrm{p}=0.02)$ and the number of children between the two groups $(\mathrm{p}=0.04)$. Comparing the two groups using independent-samples t-test, it was shown that among 12 subscales of the ENRICH questionnaire, there was a significant difference between the two groups in leisure activity $(\mathrm{p}=0.03)$ at the base line, Also, in idealistic distortion $(p<0.001)$, marital satisfaction $(p<0.001)$, personality issues $(p<0.001)$, marital relationship $(p<0.001)$, conflict resolution $(p<0.001)$, financial management $(p<0.001)$, leisure activity $(p<0.001)$, sexual relationship $(\mathrm{p}<0.001)$, relation with family and friends $(\mathrm{p}<0.001)$ at week 8 , and 10 sub scales out of 12 at the twelfth week of study had a significant difference between the two groups, all of which had a significant level of 
$\mathrm{p}<0.001$ (Table 1). Comparison of the two groups considering the 4 sub scales of the DAS questionnaire, at baseline: the level of affectional expression and marital satisfaction $(\mathrm{p}=0.01)$; at week 1: the level of affectional expression $(\mathrm{p}=0.01)$, marital satisfaction $(\mathrm{p}=0.02)$, dyadic cohesion $(\mathrm{p}=0.04)$; at week 8: dyadic consensus $(\mathrm{p}=0.001)$, affectional expression $(\mathrm{p}=0.004)$, marital satisfaction $(\mathrm{p}=0.002)$, dyadic cohesion $(\mathrm{p}=0.005)$; and at week 12: dyadic consensus $(\mathrm{p}=0.001)$, affectional expression $(\mathrm{p}=0.004)$, marital satisfaction $(\mathrm{p} \leq 0.001)$ and dyadic cohesion ( $\mathrm{p}=0.006$ ) between the two groups had a significant difference using independent-samples t-test (Table 1). Independent-samples t-test showed that among 7 sub scales of FAD questionnaires; at week 8: problem solving $(p=0.01)$, roles $(p=0.001)$, affective involvement $(p=0.003)$, behavior control $(p=0.005)$, general functioning $(\mathrm{p}=0.008)$ and at week12: problem solving $(\mathrm{p}=0.01)$, roles $(\mathrm{p}=0.001)$, affective involvement $(\mathrm{p}=0.005)$, behavior control $(\mathrm{p}=0.005)$, general functioning $(\mathrm{p}=0.006)$ has significant difference between the two groups (Table 1$)$.

Table 1. Comparisons of the mean score of DAS, FAD, and ENRICH's marital satisfaction scale in control and intervention groups.

\begin{tabular}{|c|c|c|c|c|}
\hline \multicolumn{2}{|l|}{ Variables } & $\begin{array}{l}\text { Intervention group } \\
(\mathrm{n}=18)\end{array}$ & $\begin{array}{l}\text { Control group } \\
(\mathrm{n}=18)\end{array}$ & p-value* \\
\hline \multirow[t]{5}{*}{ Mean score of ENRICH's marital satisfaction } & Baseline & $219.55( \pm 37.11)$ & $202.16( \pm 33.81)$ & - \\
\hline & Week 1 & $223.88( \pm 39.13)$ & $204.33( \pm 32.79)$ & 0.11 \\
\hline & Week 8 & $314.83( \pm 31.96)^{\dagger \diamond}$ & $226.00( \pm 38.10)^{\dagger \diamond}$ & $<0.001$ \\
\hline & Week12 & $312.44( \pm 31.42)^{\dagger \diamond \dagger}$ & $221.44( \pm 35.84)^{\dagger \dagger}$ & $<0.001$ \\
\hline & $p$-value & $<0.001$ & $<0.001$ & \\
\hline \multirow[t]{5}{*}{ Mean score of DAS } & Baseline & $87.44( \pm 24.34)$ & $70.38( \pm 19.37)$ & - \\
\hline & Week 1 & $88.88( \pm 24.89)$ & $72.22( \pm 19.17)^{\dagger}$ & 0.03 \\
\hline & Week 8 & $105.05( \pm 12.31)^{\dagger \ominus}$ & $81.83( \pm 19.77)^{\dagger}$ & $<0.001$ \\
\hline & Week12 & $104.16( \pm 11.69)^{\dagger \ominus}$ & $81.05( \pm 19.44)^{\dagger 0}$ & $<0.001$ \\
\hline & p-value & $<0.001$ & $<0.001$ & \\
\hline \multirow[t]{5}{*}{ Mean score of FAD } & Baseline & $136.83( \pm 20.27)$ & $130.66( \pm 23.47)$ & - \\
\hline & Week 1 & $137.44( \pm 39.13)$ & $136.165( \pm 21.05)$ & 0.30 \\
\hline & Week 8 & $154.44( \pm 10.27)^{\dagger \diamond}$ & $226.00( \pm 38.10)^{\dagger}$ & 0.002 \\
\hline & Week12 & $154.27( \pm 10.55)^{\dagger \ominus}$ & $135.72( \pm 20.62)^{\dagger}$ & 0.002 \\
\hline & p-value & $<0.001$ & $<0.001$ & \\
\hline
\end{tabular}

DAS: Dyadic Adjustment Scale; ENRICH: Enriching and Nurturing Relationship Issues, Communication, and Happiness; FAD: Family Assessment Device ${ }^{\dagger}$ significant difference in comparison with Baseline, ${ }^{\diamond}$ significant difference in comparison with Week $1,{ }^{*}$ significant difference in comparison with Week $8, *$ independent-samples t-test

The results of the Mann-Whitney $U$ test showed that after one week, the difference in scores was significantly increase comparing to the base line, weeks 1,8 and 12, and in the intervention group, marital satisfaction had a significant improvement over the coming weeks. The difference in scores obtained via the ENRICH scale showed that the ideal distortion between baseline and week $8(\mathrm{p}=0.03)$, as well as week 8 and $12(\mathrm{p}=0.01)$, marital satisfaction between weeks 8 and $12(\mathrm{p}=0.001)$, personality issues between baseline and week $8(\mathrm{p}=0.03)$, conflict resolution between baseline and week $12(\mathrm{p}=0.03)$, leisure activity among baseline, week 8 and week $12(\mathrm{p} \leq 0.001)$, sexual relation among baseline, week 8 and week $12(\mathrm{p}=0.003)$, parental role among baseline, week 8 and week 12 $(\mathrm{p} \leq 0.001)$, relation with family and friends between week 8 and week $12(\mathrm{p}=0.04)$, egalitarian roles among baseline, week 8 and week $12(\mathrm{p} \leq 0.001)$, and religious orientation among baseline, week 8 and week $12(\mathrm{p}=0.001)$ had meaningful differences (Table 2). Mann-Whitney U test showed that a significant difference was observed after one week, eight weeks and twelve weeks in family functioning between the intervention and control groups, but between eight and twelve, although clinical improvement was observed in family function, this difference was not statistically meaningful. The results demonstrated meaningful difference between the two groups considering the FAD scores obtained including: communication sub scale between baseline and week $8(\mathrm{p}=0.01)$, role sub scale between baseline and week $8(\mathrm{p}=0.01)$, role sub scale between baseline and week12 ( $\mathrm{p}=0.005)$, affectional responsiveness among baseline, week 8 and week $12(\mathrm{p}=0.002)$, affectional involvement among baseline, week 8 and week $12(\mathrm{p} \leq 0.001)($ Table 2$)$.

The results of the Mann-Whitney U test showed that a significant difference was observed after one week, eight weeks and twelve weeks in the adaptability of husband and wife between the intervention and control groups, which was also clinically obvious. Our results showed that marital satisfaction between week 8 and $12(\mathrm{p}=0.001)$, dyadic cohesion between week 8 and $12(p=0.04)$, dyadic consensus between baseline and week $8(p=0.002)$; baseline and 
http://www.ephysician.ir

week $12(\mathrm{p}=0.004)$ and between week 8 and $12(\mathrm{p}=0.04)$ had significant differences between the two groups (Table 2).

Table 2. Comparison the score of ENRICH, FAD, and DAS scales in different weeks between intervention and control groups.

\begin{tabular}{|l|l|l|l|l|}
\hline Comparisons & Intervention group & Control group & p-value* \\
\hline Enrich scale & Between baseline and week 1 & $4.33 \pm 9.61$ & $2.16 \pm 3.09$ & 0.19 \\
\cline { 2 - 5 } & Between baseline and week 8 & $95.27 \pm 47.16$ & $23.83 \pm 12.17$ & 0.01 \\
\cline { 2 - 5 } & Between baseline and week 12 & $92.88 \pm 46.82$ & $19.27 \pm 11.60$ & 0.01 \\
\cline { 2 - 5 } & Between Week 1 and week 8 & $90.94 \pm 48.68$ & $21.66 \pm 12.59$ & 0.009 \\
\cline { 2 - 5 } & Between week 8 and week 12 & $2.38 \pm 3.25$ & $4.55 \pm 6.47$ & 0.02 \\
\cline { 2 - 5 } & Between week 1 and week 12 & $88.55 \pm 48.51$ & $17.11 \pm 12.05$ & 0.005 \\
\hline FAD scale & Between baseline and week 1 & $1.24 \pm 0.61$ & $0.61 \pm 4.50$ & 0.20 \\
\cline { 2 - 5 } & Between baseline and week 8 & $14.40 \pm 17.61$ & $5.89 \pm 5.50$ & 0.001 \\
\cline { 2 - 5 } & Between baseline and week 12 & $13.79 \pm 17.44$ & $5.05 \pm 6.15$ & 0.001 \\
\cline { 2 - 5 } & Between Week 1 and week 8 & $15.04 \pm 17.0$ & $6.11 \pm 4.72$ & $\geq 0.001$ \\
\cline { 2 - 5 } & Between week 8 and week 12 & $1.29 \pm 0.16$ & $0.44 \pm 1.29$ & 0.70 \\
\hline DAS scale & Between baseline and week 1 & $2.47 \pm 1.44$ & $1.83 \pm 1.85$ & 0.72 \\
\cline { 2 - 5 } & Between baseline and week 8 & $18.09 \pm 17.61$ & $6.18 \pm 13.44$ & 0.008 \\
\cline { 2 - 5 } & Between baseline and week 12 & $13.79 \pm 17.44$ & $5.05 \pm 6.15$ & 0.001 \\
\cline { 2 - 5 } & Between Week 1 and week 8 & $18.39 \pm 16.16$ & $11.61 \pm 5.96$ & 0.003 \\
\cline { 2 - 5 } & Between week 8 and week 12 & $2.42 \pm 0.88$ & $2.77 \pm 4.13$ & 0.009 \\
\hline
\end{tabular}

*Mann-Whitney U test

\section{Discussion}

Unsatisfying marriage is the most common complain that increases divorce rate, it should be noted that divorce is not the only sign of an unwelcome marriage furthermore, numerous couples don't get divorce but feel unhappy. This issue may have various shapes like reducing mental and physical health of the spouses, psychological distress, difficulty in performing parental duties, disturbing the social relationships and performance of spouses, developing disruptive behavior among children, verbal and physical aggression and, at last, the divorce itself (5-11). Therefore, effective interventions to increase the satisfaction and intimacy of couples should be considered, detecting efficient and effective scientific methods for obtaining this purpose may enhance the satisfaction of existing marriages, thus preventing the adverse consequences of family disturbances. Couple therapy interventions are so effective in helping couples to prevent conflicts, correct marital dissatisfaction and abrupt intimacy, increase family function and ENRICH marital relationships. One of the approaches that can be highly effective in couple therapy and marital issues is reality therapy and Glasser's theory of choice, a method for counseling, psychotherapy and psychoeducation (12).

Learning choice theory and reality therapy teaches the skills that individuals can choose to behave responsibly, as well as the impact of behavior on emotions, and helps to improve their behavioral disorder (13-19). Considering the effect of this therapeutic method in adults and lack of sufficient studies about this method's efficacy in couples, this study aimed to investigate the psychoeducation of theory of choice on couples' marital satisfaction. The results of this study showed that there was a significant difference between the mean marital satisfaction scores after 8 weeks and 12 weeks' psychotherapy sessions between the intervention and control groups. In this regard, the intervention group had a significant clinical and statistical improvement compared to the control group. Considering husbands and wives' adaptability from the beginning to the end of the study, there was a significant difference between the two groups, which was higher in the intervention group.

Comparing the family function level in 8 and 12 weeks after sessions, there was a significant difference between the intervention and control groups. In this regard, the intervention group had a significant clinical and statistical improvement compared to the control group. This study is the first clinical trial that examines the theory of choice on marital satisfaction and couples' adaptability. Therefore, similar studies have been used for discussion. In a study conducted by Bokharaie et al. in 2006, results showed that education of reality therapy and choice theory is effective in reducing marital conflicts, which is also consistent with the results of our study (24). Given Glasser's theory of choice in couple therapy and reducing conflict and increasing couples' commitment, it can be pointed out that marriage destruction results from psychological control in marital relationships. When this type of control governs 
husband-wife relationships, the most beneficial aspect that provides the chance for recovery and improvement of life is applying the internal control psychology based on the theory of choice and accepting the responsibility. The choice theory explains how to make choices of behavior by trying to balance needs. According to the theory of choice, human control over one's behavior is a conscious control. Individuals choose their demands, expectations, thoughts and actions so that they can create a desirable and most pleasant inner status. On the other hand, marriage is a fundamental aspect of adaptability in human life. A successful and satisfying marriage requires obtaining a high level of autonomy and the couple's adaptability. William Glasser's approach, an educational approach from the outset, was a direct and practical approach for couples which shine more brightly in couple therapy approaches during the last decade

Most married people have a high level of marital satisfaction at the beginning of their life, but in addition to the gradual decline in marital satisfaction over time, some serious problems occur in the first weeks and months of marriage and if they are not solved, can threaten marital satisfaction and stability. Farahbakhsh, et al., in their research on the efficacy of Glasser's couple therapy in reducing stress and increasing the intimacy after the perceptions of infidelity, concluded that educating choice theory, couple therapy techniques had been effective on couples' satisfaction, which is consistent with the present study (25). Ghaffari et al. performed a study in 2008 with the aim of comparing group psychotherapy based on the theory of choice and systematic motivational treatment to increase marital satisfaction on 30 married women with marital satisfaction problems. The results showed that psychotherapy based on choice theory significantly improves marital satisfaction compared to a control group (26). This result is consistent with ours. This finding can be explained according to the following issues: the choice theory emphasis on developing a sense of responsibility for satisfying couples' basic needs, the release of external control, and familiarization with the qualitative world of the spouses. Glasser believes that people get married to satisfy their basic needs (23). In his view, the problem is that it is difficult for wives to have different and unrealistic expectations about how their basic needs are satisfied to another, or the severity of their needs varies from one another. Glasser claims that if the couples are taught about their basic needs, this awareness of the needs and efforts to meet their spouse's needs can have a tremendous effect on their marital satisfaction (17). As a result, teaching the principles of choice theory, informing spouses about the severity of their needs, and creating a sense of responsibility in individuals to meet their needs can play an important role in creating and improving intimacy. Finally, regarding the study limitations, the limitations of this study were mainly due to the small sample size, it is suggested to consider a greater sample size and a longer follow-up period in future studies.

\section{Conclusions}

The results of this study suggest that choice theory psychoeducation has a significant effect on marital adaptability and satisfaction as well as family function. The results of this study clarifies that the theory of choice is useful and effective in increasing marital satisfaction and family functioning as well as the level of couples' mental health. This could be a positive step in reducing problems, increasing marital satisfaction and effective in pre and post marriage educational methods in order to prevent, enrich and strengthen the family construction. Further studies on larger samples are suggested to confirm our results.

\section{Acknowledgments:}

This paper was extracted from a psychiatry residency thesis at Mashhad University of Medical Sciences in Mashhad, Iran. The authors appreciate the warm and helpful support and cooperation provided by the staff members in the Psychiatry Department at Ibn-E-Sina Hospital.

\section{Trial Registration:}

The trial (ID: IRCT20180504039519N1) was registered in the Iranian Registry of Clinical Trials (http://www.irct.ir).

Funding:

No financial support was received by authors for the research.

\section{Conflict of Interest:}

There is no conflict of interest to be declared.

\section{Authors' contributions:}

AS and FM contributed to the conception and design of the work. ZR, MZ, and ZS performed data collection or analysis / interpretation of data. ZR and ZS drafted the manuscript and all authors revised it. All authors are accountable for all aspects of the work. 


\section{References:}

1) Greeff A. Characteristics of families that function well. Journal of family Issues. 2000;21(8):948-62.

2) Gurman AS. A framework for the comparative study of couple therapy. Clinical handbook of couple therapy. 2008:1-26.

3) Karahan TF. The effects of a couple communication program on passive conflict tendency among married couples. Kuram ve Uygulamada Egitim Bilimleri. 2007;7(2):845.

4) Yalcin M, Karahan F. The effect of couple communication program on passive conflict tendency among married couples. Department of Educational Sciences, Kuruplit/Samsun, Turkey. 2009:845-58.

5) Besharat M TA, Rezazadeh M. [Explain marital satisfaction and mental health according to coping styles]. Contemporary Psychology. 2006;1(1):48-56. [In Persian].

6) Bakhshi H AM, Khodadadizadeh A. [Correlation between marital satisfaction and depression among couples in Rafsanjan]. The Journal of Qazvin Univ of Med Sci. 2007;11(2):37-43. [In Persian].

7) Wubbolding R. Counselling with reality therapy: Routledge; 2017.

8) Sayers SL, Kohn CS, Fresco DM, Bellack AS, Sarwer DB. Marital cognitions and depression in the context of marital discord. Cognitive Therapy and Research. 2001;25(6):713-32.

9) Overbeek G, Vollebergh W, de Graaf R, Scholte R, de Kemp R, Engels R. Longitudinal associations of marital quality and marital dissolution with the incidence of DSM-III-R disorders. Journal of Family Psychology. 2006;20(2):284.

10) Kwon S-YLJH. Impulsivity, social problem-solving abilities, and communication style of adolescent internet game addicts. The Korean Journal of Clinical Psychology. 2001;20(1):67-80.

11) Hawkins DN, Booth A. Unhappily ever after: Effects of long-term, low-quality marriages on well-being. Social Forces. 2005;84(1):451-71.

12) Khalili S BS, Sahebi A,Farahani H. [Explore the impact of choice theory and reality therapy interventions on couples` marital satisfaction]. Applied Psychological Research Quarterly. 2016;7(1):1-23.

13) Glasser W. Choice theory: A new psychology of personal freedom: HarperPerennial; 1999.

14) Glasser W. Reality therapy in action: HarperCollins Publishers; 2000.

15) Burdenski Jr TK, Faulkner B, Britzman MJ, Casstevens WJ, Cisse GS, Crowell JL, et al. The Impact of the Glasser Scholars Project on Participants' Teaching and Research Initiatives: Part II. International Journal of Reality Therapy. 2009;29(1). [In Persian].

16) Wubbolding R. Counselling with reality therapy: Routledge; 2017.

17) Kim J-U. The effect of a R/T group counseling program on the Internet addiction level and self-esteem of Internet addiction university students. International Journal of reality therapy. 2008;27(2).

18) Vaziri S, Kashani FL, Jamshidifar Z, Vaziri Y, Jafari M. Group counseling efficiency based on choice theory on prisoners' responsibility increase. Procedia-Social and Behavioral Sciences. 2014;128:311-5.

19) Wubbolding RE. Reality therapy for the 21 st century: Routledge; 2013.

20) Gorbanalipour M,Najafi M,Alirezalo Z,Nasimi M.[The Effectiveness of Reality Therapy on Happiness and Hope in Divorced Women].Family consult and psychotherapy.2014;4(2):297-317. [In Persian].

21) Zeeman RD. Glasser's Choice Theory and Purkey's Invitational Education--Allied Approaches to Counseling and Schooling. Journal of Invitational Theory and Practice. 2006;12:46-51.

22) Darbay M. Reviews the effectiveness of teaching concepts theory reality therapy on increasing intimacy incompatible couples counseling centers [dissertation]. Tehran: Welfare and Rehabilitation Sciences unive. 2008;8(3):89-93. [In Persian]

23) Amani A. The Efficacy of Reality Therapy on Marital Commitment and Self Esteem of Couples. Family Counseling and Psychotherapy. 2015; 5(2): 1-23. [In Persian].

24) Bokharaei, M. The impact of group consulting with reality therapy approach on the reduction of marital conflict of housewives on Tehran 5th District. [Master Thesis]. Tehran: Al-Zahra University.2006.

25) Farahbakhsh K. Ghanbari HB. Effectiveness of Glosser couple therapy on decreasing stress and increasing of intimacy after trauma of perceived infidelity. Stud Educ Psychol. 2007; 7(2):173-90.

26) Ghaffari H. Ghanbari Hashemabadi F.Compare the effectiveness of group therapy based on the theory of selection and motivation of systematic increase in marital satisfaction. Studies and Educational Psychology.2010; 9(2): 65-78. 